\title{
Effect of Cultural Intelligence (CI) on Patient Care Services in Private Hospitals at Muscat Governorate
}

\author{
S. Porkodi, Amna Sabil AlZadjali, Fatma Salim AlRahbi, and Yasemain Mohammed AlNabhani
}

\section{ABSTRACT}

The increasing need for medical care has led to demand for private medical institutions which offer more personalized care. Most of the patients have grown to prefer private medical attention as compared to public medical care due to the better services offered. Nurses interact with patients on a daily basis who are from different cultural backgrounds which makes it essential for them to understand various cultures to be able to interact and effectively serve all the patients visiting the hospital. Private hospitals in Oman receive patients from diverse cultural backgrounds. In this research, an attempt was made to find out the level of Cultural intelligence in various dimensions and to examine the effect of nurses' cultural intelligence (CI) on patient care services in private hospitals at Muscat governorate. Hence, nurses from Muscat governorate private hospitals were the study's respondents. The data was analysed using the Quartile method, Chi-square, and multiple regression analysis. This research found that the nurses have high level of cultural intelligence in cognitive and meta-cognitive dimensions. On the other hand, majority of the respondents had low level of behavioural dimension of cultural intelligence. And there is no significant relationship between demographic details and the level of cultural intelligence. Furthermore, the findings demonstrated a significant relation between nurse's cultural intelligence in various dimensions and patient care services.

Keywords: Behavioral dimension, Cognitive dimension, Metacognitive dimension, Motivational dimension.

\section{INTRODUCTION}

Cultural intelligence is the skill and ability to work and relate effectively in places and situations which are culturally diverse (Steyn and Solomon, 2017). Dimensions of cultural intelligence comprises of cognitive, metacognitive, behavioral, and motivational (Charoensukmongkol and Pandey, 2020). Having cultural intelligence helps in acquiring in depth understanding of the practices, beliefs, and values of other cultures (Gabel-Shemueli, 2019). At work, cultural intelligence helps a person understand each other which cultivates their relationship leading to better results. People are able to demonstrate better trust, tolerate as well as understanding of people from different cultural backgrounds. Oman is one of the most effective countries at dealing with both the good and poor timing of the financial instability situation, because with its multiculturalism. A good example is the opacity of many cultural backgrounds in the workplace (AlRaisi et al., 2019).

The health sector in Oman is one of most significant sectors as it plays an important role in ensuring the wellbeing of its community members by providing adequate care. Hospitals in Oman provide quality health care services. Muscat Governorate has the most advanced as well as the largest hospitals in the country such as Sultan Qaboos University Hospital and Royal Hospital of Oman. According to the National Centre for Statistics \& Information (NCSI)
2020, The below Table I, provide the details of total number of government and private Sectors hospitals and health units distributed by governorates and number of beds in Oman.

TABLE I: TOTAL NumBer of GOVERNMENT AND PRIVATE SECTORS HOSPITALS AND HEALTH UNITS DISTRIBUTED BY GOVERNORATES AND NUMBER OF BEDS IN OMAN

\begin{tabular}{cccccc} 
& \multicolumn{3}{c}{ Private Sector } & \multicolumn{2}{c}{$\begin{array}{c}\text { Government } \\
\text { Sector }\end{array}$} \\
\hline & \multicolumn{2}{c}{ Health } & Hospitals & Hospitals \\
\cline { 2 - 6 } Governorates & Clinics & Beds & Units & Beds & Units \\
\cline { 2 - 6 } & 420 & 615 & 17 & 2694 & 11 \\
& 64 & 85 & 3 & 683 & 9 \\
Muscat & 10 & 0 & 0 & 158 & 3 \\
Dhofar & 24 & 0 & 0 & 150 & 2 \\
Musandam & 65 & 56 & 1 & 556 & 7 \\
Al Buraymi & 132 & 134 & 2 & 461 & 5 \\
AD Dakhliyah & 45 & 122 & 3 & 298 & 5 \\
Al Bathinah North & 35 & 0 & 0 & 398 & 4 \\
Al Bathinah South & 25 & 0 & 0 & 367 & 6 \\
ASH Sharqiyah South & 82 & 42 & 1 & 272 & 2 \\
ASH Sharqiyah North & 45 & 0 & 0 & 77 & 3 \\
ADH Dhahirah & 947 & 1054 & 27 & 6114 & 57 \\
Al Wusta & & & & & \\
Total & & &
\end{tabular}

Nurses are regarded as an extremely important part of the hospital staff because they directly deal with the pain and recovery of patients (Porkodi and Haque, 2012). They interact with patients on a daily basis who are from different cultural backgrounds which makes it essential for them to understand various cultures to be able to interact and effectively serve all the patients visiting the hospital. 


\section{Problem Statement}

Due to an increase in diseases and a growing population, the hospital industry in the Sultanate of Oman has grown tremendously. The increasing need for medical care has led to demand for private medical institutions which offer more personalized care. Brant et al. (2021) reports that private hospitals in Oman have prioritized patient care. As such, it is essential to ensuring the comfort of patients and ensuring they have a good environment during their recovery. Most of the patients have grown to prefer private medical attention as compared to public medical care due to the better services offered. The nurses are responsible for taking care on the patients in the hospitals (AlUbaidi et al., 2020). According to the Australian Industry and Skills Committee (2020), nurses play an important role in all health sectors because they provide essential pre-hospital and out-of-hospital care. Services can be provided in both emergency and nonemergency situations, and nurses in hospitals play important roles in terms of injury/illness prevention and determining patients' health because they are highly trained to provide healthcare directly to patients.

Patients from various cultural backgrounds are treated in Oman's private hospitals. The nurses have struggled to understand the cultural background of different patients, which makes it difficult for them to help them in the best way possible (Barzykowski et al., 2019). This is because patients from different cultures behave differently and also have a different perception on various issues making it difficult for nurses without knowledge about their culture to serve them appropriately. Nursing employees have interacted with patients despite their cultural differences with the patients which has been a challenge in understanding one another (AlUbaidi et al., 2020). This led to necessity of studying the effect of nurse's cultural intelligence on the patient care services in the private hospitals at Muscat Governorate.

\section{OBJECTIVES}

1. To examine the relationship between nurse's demographic factors (gender, age group, educational level, experience, department) and the level of cultural intelligence in private Hospitals at Muscat Governorate.

2. To evaluate the effect of nurse's cultural intelligence (cognitive dimension, metacognitive dimension, motivational dimension, and behavioral dimension) on the patient care services in private hospitals at Muscat Governorate.

\section{REVIEW OF LITERATURE}

People from various regions have different cultural practices which shape their values and ethics. Through studying different cultures, people are able to demonstrate better trust, tolerate as well as understanding of people from different cultural backgrounds (Göl, and Erkin, 2019). According to Charoensukmongkol and Pandey, 2020) cultural intelligence is also known as cultural quotient in business. It is a theory in organizational and management psychology stating that the ability of a person to understand cultural behavior is key to understanding the people from different cultural backgrounds.
Cultural norms are the shared, integrated beliefs, sanctioned and practices associated with a certain cultural group. The shared norms offer guidelines for daily living and attribute to the well-being of the group. Cultural norms conciliate the relationship between health and ethnicity, marriage rules, environmental exposure, and lifestyle choices (Al Sabei et al., 2021). Cultural norms act as the standard guide through which various cultures use in their daily activities (Rahimaghaee and Mozdbar, 2017). Understanding the diversification of different cultures is core in the health sector since nurses have the knowledge pertaining cultural intelligence. Understanding the various cultural backgrounds of patients within the health sector boost the relationship between staff and patients (Sohal et al., 2021). The approach and interaction of patients and staff is key since patients require nurses who fully understand their cultural settings to help in creating a conducive environment within the health sector (Afsar et al., 2019). Behavioral cultural intelligence is the ability to exhibit proper nonverbal and verbal actions when you are interacting with people coming from different cultural background. Patients prefer nurses who can blend and communicate in their language and not knowing the entire languages but understanding a few phrases to keep the conversations going to make the patients feel comfortable and at ease in the hospital it promotes cultural diversity (Maestri, 2021). Having an intrinsic interest in diverse cultures motivates individuals towards learning the differences and similarities which exist among cultures. Motivated individuals put a lot of effort in understanding various cultures and are persistence which makes them end up performing better as compared to unmotivated individuals (Charoensukmongkol and Pandey, 2020).

Gender affects the behavior and the way of thinking of individuals. Females tend to be more sensitive in general as compared to males. The attitude and behaviors of people depend on their upbringing as well as cultural backgrounds (Williams, 2017). Another reason to expect women to exceed men on Cultural intelligence is their superior verbal intelligence and fluency in both their native language and other languages. Comprehension diverse cultures may benefit from a greater understanding of foreign languages. As a result, women may have higher Cultural intelligence in that regard (Ziada et al., 2021). Likewise, age plays a major role in cultural intelligence. Older people understand the norms, practices and behaviors of people from different communities more compared to young people (Jiang and Gollan, 2018). Moreover, the age of a person determines their view on issues as well as what they see as important. Younger people tend to be energetic and less understanding as compared to older people who are calmer and more understanding (Steyn and Solomon, 2017). Similary, education and cultural intelligence are interdependent and inseparable parameters. All the educational patterns are guided by the cultural patterns in the society. People who are more educated tend to understand the challenges that people in different professionals go through as compared to the lesser educated individuals (Caputo et al., 2019). Also, the more educated people are able to identify when the services offered to them are low quality.

The majority of past study has been conducted on the cultural intelligence or cultural competence of nurses. These prior studies did not examine the effect of cultural 
intelligence on patient care services across all four dimensions. Furthermore, the studies have not examined the association between demographical characteristics and cultural intelligence aspects among nurses. As a result, this study concentrated on this research gap in the context of Oman.

TABLE II: SUMMARY OF THE LITERATURE REVIEW

\begin{tabular}{|c|c|c|}
\hline Authors & Focus Area & Highlights of the Study \\
\hline $\begin{array}{l}\text { Göl, and Erkin, } \\
\text { (2019) }\end{array}$ & $\begin{array}{l}\text { The purpose of the study was to determine whether cultural } \\
\text { sensitivity and cultural intelligence are related. }\end{array}$ & $\begin{array}{l}\text { The research highlighted that higher level of cultural } \\
\text { intelligence increases intercultural sensitivity. }\end{array}$ \\
\hline $\begin{array}{l}\text { Charoensukmong } \\
\text { kol and Pandey } \\
(2020)\end{array}$ & $\begin{array}{l}\text { The purpose of this research is to investigate the impact of cross- } \\
\text { cultural salespeople's cultural intelligence (CQ) on the quality of } \\
\text { cross-cultural sales presentations (CSSP). }\end{array}$ & $\begin{array}{l}\text { The findings support sales-efficacy partially mediates the } \\
\text { relationship between Cultural intelligence quotients and } \\
\text { CSSP. }\end{array}$ \\
\hline $\begin{array}{l}\text { Al Sabei et al., } \\
(2021)\end{array}$ & $\begin{array}{l}\text { The impact of the work environment, inter-professional } \\
\text { teamwork, and staffing levels on adverse patient events was } \\
\text { investigated in this study, as well as the predictive factors of } \\
\text { nurses' opinions of the work environment in the Sultanate of } \\
\text { Oman. }\end{array}$ & $\begin{array}{l}\text { According to this study, nurses employed in a pleasant } \\
\text { environment with good cooperation reported fewer adverse } \\
\text { events, patient verbal abuse, and patient falls. }\end{array}$ \\
\hline $\begin{array}{l}\text { Rahimaghaee and } \\
\text { Mozdbar (2017) }\end{array}$ & $\begin{array}{l}\text { Studying the relationship between cultural intelligence and } \\
\text { professional competence was the purpose of this study. }\end{array}$ & $\begin{array}{l}\text { Nurses' professional competence is positively correlated with } \\
\text { cultural intelligence. Additionally, the metacognitive } \\
\text { dimension displayed the most predictive power for } \\
\text { professional competency. }\end{array}$ \\
\hline Sohal et al., (2021) & $\begin{array}{l}\text { In the study, lean is investigated in the healthcare sector of a } \\
\text { developing country, specifically Oman. }\end{array}$ & $\begin{array}{l}\text { The authors discovered that Oman's healthcare sector is good } \\
\text { in terms of } \\
\text { value understanding, and customer groupings. }\end{array}$ \\
\hline Afsar et al., (2019) & $\begin{array}{l}\text { The association between cultural intelligence and voice behavior } \\
\text { was examined in this study. }\end{array}$ & $\begin{array}{l}\text { This study provides a new perspective on the relationship } \\
\text { between cultural intelligence and speech behavior. }\end{array}$ \\
\hline Ziada et al., (2021) & $\begin{array}{l}\text { In this study, cross-cultural and gender disparities in CI were } \\
\text { investigated. }\end{array}$ & $\begin{array}{l}\text { Findings revealed an intriguing pattern of gender and country } \\
\text { cultural relationships. }\end{array}$ \\
\hline $\begin{array}{l}\text { Jiang and Gollan, } \\
\text { (2018) }\end{array}$ & $\begin{array}{l}\text { The research examined at cultural intelligence (CQ) as a predictor } \\
\text { of vocal conduct. }\end{array}$ & $\begin{array}{l}\text { The effects of CQ on employee voice were confirmed by } \\
\text { these data. }\end{array}$ \\
\hline $\begin{array}{l}\text { Caputo et al., } \\
(2019)\end{array}$ & $\begin{array}{l}\text { The impact of cultural intelligence on the relationship between } \\
\text { cultural values and individual preferences for a certain } \\
\text { negotiation style is investigated in this study. }\end{array}$ & $\begin{array}{l}\text { The research emphasized the impact of cultural values and } \\
\text { intellect on negotiation techniques. }\end{array}$ \\
\hline
\end{tabular}

\section{CONCEPTUAL FRAMEWORK}

Fig. 2 represents the conceptual framework of this research study. H1, H2, H3, H4 are the hypothesis of this conceptual model. Demographic factor considered as controlled variable in this study.

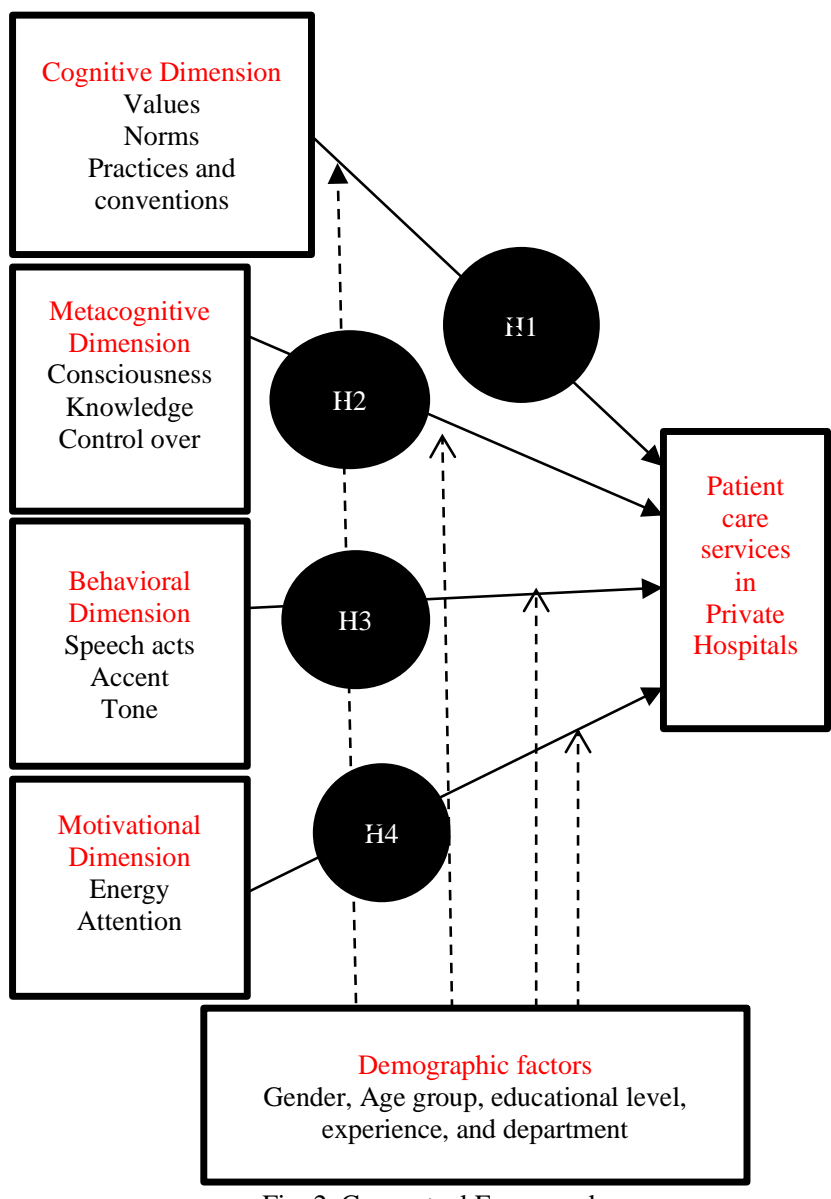

Fig. 2. Conceptual Framework.

\section{HYPOTHESIS OF THE STUDY}

To measure the impact on patient care services, the research hypothesis was developed based on the four dimensions of cultural intelligence. The hypothesis are as follows:

H01: There is no significant relation between cognitive dimension of cultural intelligence and the patient care service.

H02: There is no significant relation between metacognitive dimension of cultural intelligence and the patient care service.

H03: There is no significant relation between motivational dimension of cultural intelligence and the patient care service.

H04: There is no significant relation between behavioural dimension of cultural intelligence and the patient care service.

\section{RESEARCH METHODOLOGY}

The study employed a descriptive research design. It describes the characteristics of cultural intelligence's (CI) impact on patient care services in a private hospital in the Muscat governorate. A questionnaire was utilized as a data collection tool. The researchers developed a questionnaire with 30 statements with Likert's five (5) point scale for respondents to give their opinions on the subject. The questionnaire is divided into two sections, one of which comprises demographic information. The second section covers statements related to four dimensions of Cultural intelligence and patient care services. The researchers embraced the cultural intelligence scale developed by (Ang and Van Dyne, 2006) and considering the nature of nurses' job, the statements were modified, and few statements were 
added according to the need of the study. The cultural intelligence dimension comprises of metacognitive CI, cognitive CI, motivational CI, and behavioral CI. Each dimension in the questionnaire consists of 5 statements. Finally, the questionnaire end with 10 questions about patient care services.

In this investigation, the researchers used a non-probability snowball sampling technique. Nurses from Muscat governorate private hospitals are the study's target respondents. According to health sector statistics (2020), Oman has a total of 84 hospitals, with 10 private hospitals in Muscat Governorate. According to figures from the NCSI health sector (2020), there are 3960 nurses employed in the private sector. Only 2.88 percent (114) of the 3960 total nurses are Omani nurses, with 97.12 percent (Expatriate:3846) coming from various cultural backgrounds. After consulting experts and using sample size formula, the researchers decided on a sample size of "150" nurses in private hospitals. Six surveys were found to be missing after the data was collected. As a result, 144 samples were chosen for final analysis. The gathered data was analyzed using the SPSS V26 statistical software. To examine the strength and value of the data, various methods were utilized, including the quartile method, Chi square, means score, and multiple regression analysis.

\section{ANALYSIS OF DATA}

The reliability of the statements used in the questionnaire concerning the dimensions of cultural intelligence and patient care services is calculated and presented in the Table III below.

TABLE III: RELIABILITY STATISTICS

\begin{tabular}{cccc}
\hline Constructs & $\begin{array}{c}\text { No. of } \\
\text { Items }\end{array}$ & $\begin{array}{c}\text { No. of } \\
\text { respondents }\end{array}$ & $\begin{array}{c}\text { Reliability Statistics } \\
\text { (Cronbach's Alpha) }\end{array}$ \\
\hline $\begin{array}{c}\text { Cognitive } \\
\text { Dimension }\end{array}$ & 5 & 144 & 0.948 \\
$\begin{array}{c}\text { Meta-Cognitive } \\
\text { Dimension }\end{array}$ & 5 & 144 & 0.901 \\
$\begin{array}{c}\text { Motivation } \\
\text { Dimension } \\
\text { Behavior }\end{array}$ & 5 & 144 & 0.850 \\
Dimension & 5 & 144 & 0.863 \\
$\begin{array}{c}\text { Patient Care } \\
\text { Services }\end{array}$ & 10 & 144 & 0.942 \\
Overall & 30 & 144 & 0.955 \\
\hline
\end{tabular}

Source: Primary Data.

The overall reliability score was $(0.955)$, indicating that the construct is highly reliable.

The Table IV below highlights the demographic detail of the respondents; the variables taken for the study are Gender, Age, Education level, Experience in Oman, Ward detail and Department.

Gender: $60.4 \%$ are female respondents and $39.6 \%$ are male respondents, it means that most of the nursing respondents are female communal.

Age: $15.3 \%$ of the respondents are below 25 years. Were $36.8 \%$ of the respondents are between 26 to 35 years. In addition, the age group from 36 to 45 years represents $24.3 \%$. Remaining $16 \%$ of the respondents are from 46 to 55 years and only $7.6 \%$ of the respondents are above 55 years. It means the majority of nursing respondents are from 26 to 35 years.

Educational level: majority of nurse respondents are holding bachelor level by $38.9 \%$ of the study and $29.2 \%$ hold master level the remains $31.9 \%$ have other degrees.

Experience in Oman: $20.1 \%$ of nurse respondents have less than one year of experience in Oman, whereas $31.3 \%$ are with 1 to 5 years of experience. Hence $27.1 \%$ are having experience from 6 to 10 years and the rest $21.5 \%$ of the respondents with more than 10 years of experience.

Ward details: majority of the respondents are working in the inpatient ward which are around $54.2 \%$ whereas, $45.8 \%$ are working in the outpatient ward.

Department: $14.6 \%$ of the respondents are working in the ICU department, $18.8 \%$ in General department, $11.1 \%$ in Dermatology, $11.8 \%$ in Cardiology, $16.7 \%$ in Pediatrics, $10.4 \%$ in Psychiatry, $16.7 \%$ working in other departments.

The level of Cultural intelligence in four dimensions (metacognitive CI, cognitive CI, motivational CI, and behavioral $\mathrm{CI}$ ) among nurses in Muscat Governorate private hospitals was calculated and reported in Tables V and VI.

TABLE IV: DEMOGRAPHIC PROFILE OF RESPONDENTS

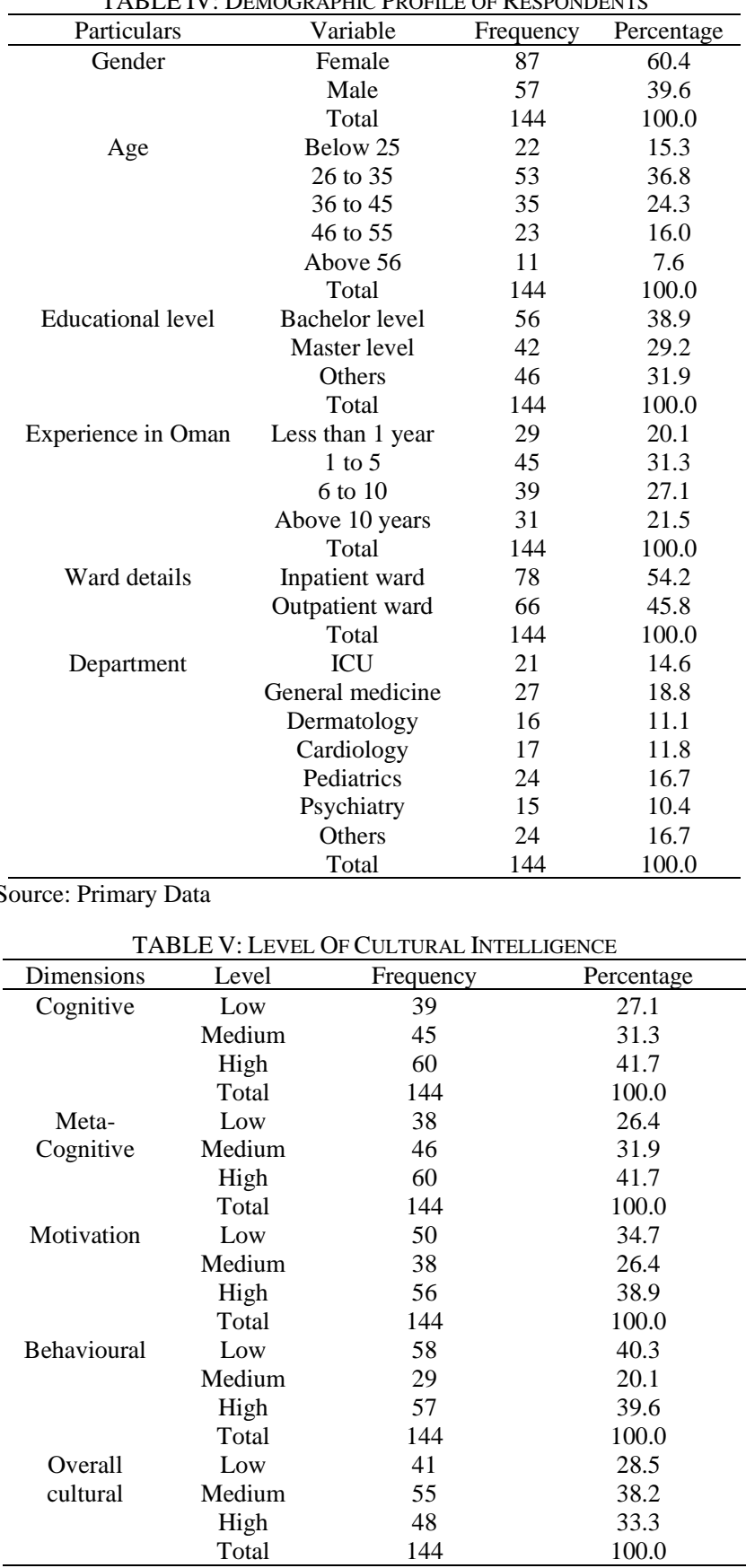

Source: Computed Data. 
TABLE VI: LEVEL OF CULTURAL INTELLIGENCE WITH DEMOGRAPHIC FACTORS

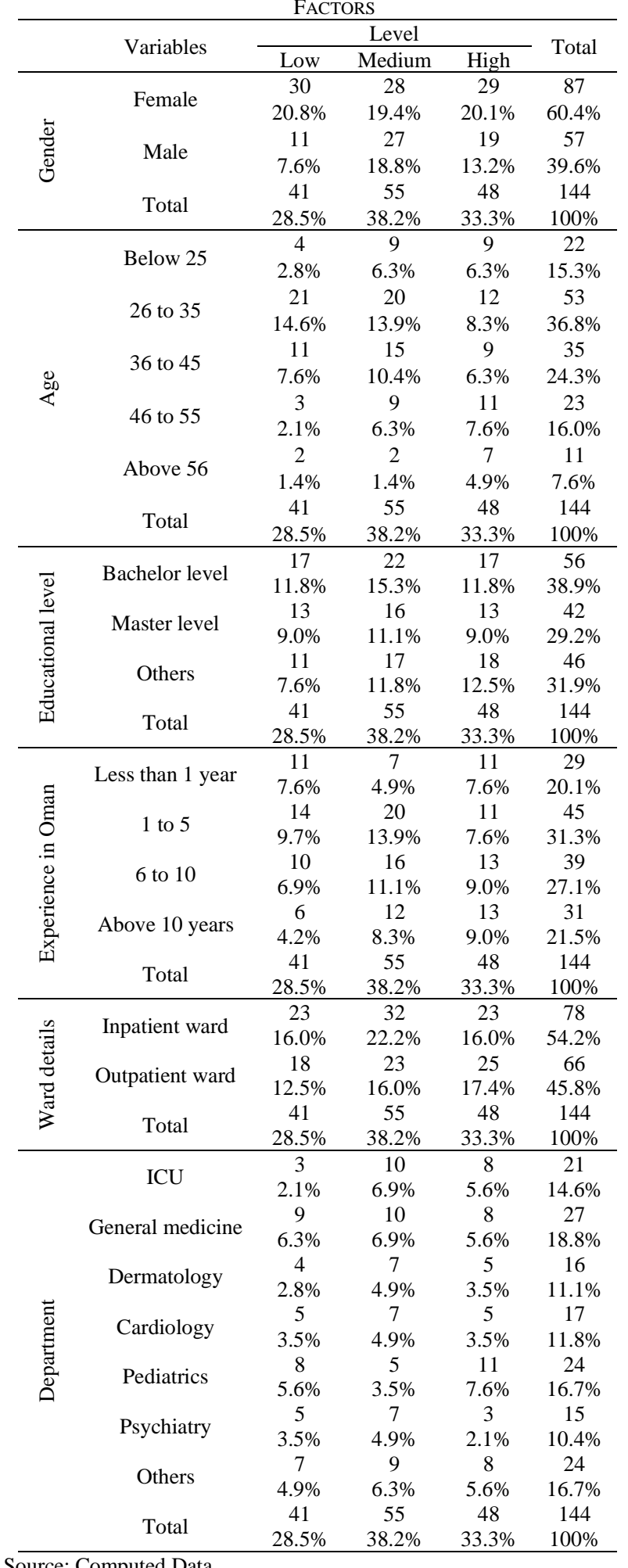

Source: Computed Data.

Cognitive: Nurses who are the respondents of this research having high level of cultural intelligence in the cognitive dimension which is around $41.7 \%$ and $31.25 \%$ of nurses having medium level of cognitive dimension, the remaining $27.08 \%$ are having low level of cognitive dimension.

Meta-Cognitive: $41.67 \%$ of the respondents having high level of cultural intelligence in the meta-cognitive dimension. In addition, $31.94 \%$ having medium level of meta-cognitive. On the other hand, the rest $26.39 \%$ of the respondents having low level of cultural intelligence in the meta-cognitive dimension.
Motivation: The high level of motivational cultural dimension of nurse respondents by $38.89 \%$, Medium level by $26.39 \%$, Low level by $34.72 \%$.

Behavioural: $40.28 \%$ of the respondents are having low level of cultural intelligence in the behavioral dimension, $39.58 \%$ are having high level, and $20.14 \%$ are having medium level of cultural intelligence in the behavioral dimension. The reason could be the nurses might feel difficult to speak the different languages of patients from diversified culture.

Overall cultural intelligence level: The majority of the respondents are having medium level of cultural intelligence in all the dimensions which is $38.19 \%$. On the other hand, $33.33 \%$ respondents are having high level and $28.47 \%$ only having low level of cultural intelligence in all the dimensions.

From the below Table VI, Gender: $20.8 \%$ of female respondents and $7.6 \%$ of the male respondents show up the low level of cultural intelligence. On the other hand, $20.1 \%$ of female respondents and $13.2 \%$ male respondents view the level of cultural intelligence are having high level. In addition, $19.4 \%$ of female respondents and $18.8 \%$ of male respondents are the highest percentage of the research respondent show up the level of cultural intelligence is having medium level.

Age: Majority of respondents represents the level of age group and the level of cultural intelligence is having low level, by $14.6 \%$ of the respondent between 26 to 35 age group. In addition, only $1.4 \%$ of the age group above 55 years view the cultural intelligence is having both low and medium level.

Educational level: majority of respondents the level of educational and the level of cultural intelligence are having medium level by $15.3 \%$ of the respondents holding bachelor level. On the other hand, only $7.6 \%$ of the respondents holding other level view the cultural intelligence having low level.

Experience in Oman: majority of nurses with 1 to 5 years experiences in the hospital having medium level, by $13.9 \%$ of the cultural intelligence, $6.9 \%$ of the respondents with 6 to 10 years. In addition, only $4.2 \%$ of the respondents with above 10 years having low level.

Ward details: $22.2 \%$ of the respondents are having medium level of inpatient ward. On the other hand, $12.5 \%$ of the respondents having low level of outpatient ward.

Department: most research nursing respondents view the level of cultural intelligence to be high, by $7.6 \%$ of the respondent works in the pediatrics department, $6.9 \%$ in General department, $3.5 \%$ in Dermatology, $4.9 \%$ in Cardiology, $16.7 \%$ in Pediatrics, $10.4 \%$ in Psychiatry. In addition, only $2.1 \%$ works in ICU and Psychiatry having low and high level.

Furthermore, the hypothesis was tested using the Pearson Chi-square test in order to investigate the association between the demographic variables of the respondents and their level of cultural intelligence. The results of the hypothesis test were presented in Table VII. The study's hypothesis is as follows:

$\mathrm{H} 0$ : There is no significant relation between demographic factors (gender, age group, educational level, experience, department) and the level of the cultural intelligence in private hospitals at Muscat Governorate.

From Table VII, the result displays that the $\mathrm{p}$ values $(0.088$, $0.075,0.875,0.421,0.556,0.842)$ which are more than 0.05 
( $p>0.05)$, and the chi-square $(4.868,14.261,1.216,6.019$, $1.174,7.233 \mathrm{a})$ respectively, suggest that there is no significant relationship between demographic variables and the level of cultural intelligence, hence the null hypothesis is accepted. It means there is no significant relation between the demographic variables of the respondents and the level of cultural intelligence.

TABLE VII: TESTING OF HYPOTHESIS (CHI-SQUARE)

\begin{tabular}{ccccc}
\hline $\begin{array}{c}\text { Demographic } \\
\text { Variable }\end{array}$ & Value & d.f & $\begin{array}{c}\text { P } \\
\text { Value }\end{array}$ & $\begin{array}{c}\text { Significance at } \\
5 \%\end{array}$ \\
\hline Gender & 4.868 & 2 & 0.088 & Not significant \\
Age & 14.261 & 8 & 0.075 & Not significant \\
Educational level & 1.216 & 4 & 0.875 & Not significant \\
Experience in Oman & 6.019 & 6 & 0.421 & Not significant \\
Ward details & 1.174 & 2 & 0.556 & Not significant \\
Department & 7.233 & 12 & 0.842 & Not significant \\
\hline Source: Computed Data & & & &
\end{tabular}

Furthermore, the effect of nurses' cultural intelligence (metacognitive CI, cognitive CI, motivational CI, and behavioural $\mathrm{CI}$ ) on patient care services in private hospitals in Muscat Governorate was assessed using multiple regression analysis.

TABLE VIII: TESTING OF HYPOTHESIS (MULTIPLE REGRESSION)

\begin{tabular}{|c|c|c|c|c|c|}
\hline \multirow{2}{*}{ Dimension } & \multicolumn{2}{|c|}{$\begin{array}{l}\text { Unstandardised } \\
\text { coefficients }\end{array}$} & \multirow{2}{*}{$\begin{array}{c}\begin{array}{c}\text { Standardised } \\
\text { coefficients }\end{array} \\
\text { beta }\end{array}$} & \multirow{2}{*}{$\mathrm{t}$} & \multirow{2}{*}{ Sig } \\
\hline & B & $\begin{array}{l}\text { Std. } \\
\text { Error }\end{array}$ & & & \\
\hline Constant & 3.517 & 0.406 & & 8.667 & 0.000 \\
\hline X1 & 0.377 & 0.062 & 0.009 & 2.105 & \\
\hline $\mathrm{X} 2$ & 0.451 & 0.053 & 0.086 & 4.969 & \\
\hline X3 & 0.391 & 0.066 & 0.121 & 1.372 & $\dot{*} *$ \\
\hline $\mathrm{X} 4$ & 0.262 & 0.067 & 0.081 & 5.928 & 0 \\
\hline
\end{tabular}

a. Dependent Variable: Patient Care Services a Note: **sig. at $1 \%$ level Source: Computed Data.

Multiple R value: 0.980 .

R square value: 0.906 .

F value: 85.508 .

P value: $<0.001 * *$

The coefficient value of $0.980(98 \%)$ suggests that the link between patient care services and the four independent variables is fairly strong and positive in the Cognitive dimension, Meta Cognitive dimension, Motivation dimension, and Behavioural dimension of the cultural intelligence. Thus, the value of $\mathrm{R}$ square is 0.906 , explains approximately 90.6 percent of the variation in patient care services, and the R square value is significant at the $1 \%$ level.

The Multiple regression equation is:

$$
\mathrm{Y}=\mathrm{C}+\mathrm{f}(\mathrm{X} 1+\mathrm{X} 2+\mathrm{X} 3+\mathrm{X} 4)
$$

where

$\mathrm{Yi}=$ Patient care services;

$\mathrm{X} 1$ = Cognitive Dimension of Cultural Intelligence;

$\mathrm{X} 2$ = Meta Cognitive Dimension of Cultural Intelligence;

X3 = Motivation Dimension of Cultural Intelligence;

X4 = Behavioural Dimension of Cultural Intelligence.

From Table VIII, the results indicate that the variable X1 representing the cognitive dimension of cultural intelligence and the $\mathrm{p}$ value is $\mathrm{p}<0.001 * *$, which is significant at $1 \%$ level, indicating that there is a relation between patient care services and the cognitive dimension of cultural intelligence. As well as X2 demonstrating the meta cognitive dimension of cultural intelligence and the $\mathrm{p}$ value is $\mathrm{p}<0.001^{* *}$, which is significant at $1 \%$ level, denoting that there is a relation between patient care services and the meta cognitive dimension of cultural intelligence. Also, the item X3 representing the motivation dimension of cultural intelligence and the $p$ value is $\mathrm{p}<0.001^{* *}$, which is significant at $1 \%$ level, revealing that there is a relation between patient care services and the motivation dimension of cultural intelligence. The variable $\mathrm{X} 4$ signifying the behavioural dimension of cultural intelligence and the $\mathrm{p}$ value is $\mathrm{p}<0.001 * *$, which is significant at $1 \%$ level, representing that there is a relation between patient care services and the behavioural dimension of cultural intelligence. Hence, for all the null hypothesis rejected and the alternative hypothesis accepted for all the four independent variables. It infers from this multiple regression analysis, that the four dimensions (Cognitive Dimension (X1), Meta Cognitive Dimension (X2), Motivation Dimension (X3), and Behaviour Dimension (X4)) of cultural intelligence are significantly related with the good patient care services.

\section{CONCLUSION AND IMPLICATIONS}

It is imperative for every pioneering healthcare organization to invest in the development of nurses' skills and competencies. Cultural intelligence is considered an invaluable capability for nurses because they encounter patients from different cultures. The impact of cultural intelligence on nursing is a vast topic that has been researched in various ways, with only a few academics looking into different aspects of cultural intelligence. Many studies have been done on nurses' cultural competency and cultural intelligence (AlBusaidi et al., 2019; Afsar et al., 2019; Rahimaghaee et al, 2017; AlUbaidi et al, 2020). Only a few studies (Fata et al., 2017; Göl, \& Erkin, 2019; and Rahimaghaee et al., 2017) looked at the impact of cultural intelligence solely. The impact of cultural intelligence on job satisfaction and organizational commitment among nurses was explored by Fata et al., (2017). Göl and Erkin (2019) studied the cultural intelligence and sensitivity of nurses. Rahimaghaee et al. (2017) also looked into the link between cultural intelligence and nursing cultural competency. None of the research, however, looked into how a nurse's cultural intelligence influenced patient care. Henceforth, the purpose of this study was to analyse the four dimensions of cultural intelligence and the effect of cultural intelligence (CI) on patient care services in private hospitals in Muscat, Oman. The level of cultural intelligence was measured in all four dimensions in this comprehensive study. The research was carried out at private hospitals and focuses on nurses as they are the most important party in the healthcare industry as their day-to-day employment requires them to interact with a wide range of patients.

As the questionnaire includes statements to test how these dimensions are impacting nursing personnel in their patient care services in the private sector, the study's findings revealed that nurses show a high level of cultural intelligence in both cognitive and meta-cognitive dimensions. On the other hand, the majority of respondents had a low level of cultural intelligences in behavioral dimension. In terms of overall cultural intelligence level, $38.19 \%$ of respondents had 
a medium degree of cultural intelligence across all categories. Furthermore, there is no statistically significant association between demographic characteristics (Gender, Age Group, Educational Level, Experience, Ward Details, Department) and cultural intelligence. Finally, as a result, this study conducted multiple regression analyses to examine the effect of nurse's cultural intelligence in all four dimensions on patient care services. The findings demonstrated a significant association between nurse cultural intelligence and patient care services.

Understanding the effect of nurse's cultural intelligence enhances good patient care services. With a better relationship between nurses and patients, the care services will be better managed, allowing both parties to be satisfied. This research will help to health sector administrators for improving some aspects which will improve the efficiency of patient care services and also to motivate the nurses to improve their services to their patients.

\section{ACKNOWLEDGMENT}

Based on their thesis submitted to the University of Technology and Applied Science in Muscat, Oman, the authors developed this article. They would like to express their gratitude to the Vice Chancellor, Dean, the Head of the Business Department, all other university officials, and staff, as well as Hospital administrators and nurses, for their enthusiastic participation and support in this study.

\section{REFERENCES}

Afsar, B., Shahjehan, A., Shah, S.I. and Wajid, A., (2019). The mediating role of transformational leadership in the relationship between cultural intelligence and employee voice behavior: A case of hotel employees. International Journal of Intercultural Relations, 69, pp.6675 .

Ahmed, W., \& Bilal, A. (2017). The Impact of Emotional Intelligence on Job Satisfaction and Performance in the Healthcare Sector of Pakistan.

Al-Busaidi, I. S., Al Suleimani, S. Z., Dupo, J. U., Al Sulaimi, N. K., \& Nair, V. G. (2019). Nurses' knowledge, attitudes, and implementation of evidence-based practice in Oman: A multi-institutional, cross-sectional study. Oman medical journal, 34(6), 521.

Al Harthy, S. N., Tuppal, C. P., Ana, A. E. S., Reynecke, J., Al Husami, I., \& Al Rubaiey, A. (2018). Interprofessional competency framework for health service managers in Oman: an e-Delphi study. Oman medical journal, 33(6), 486.

Al-Hawary, S. I., \& Banat, N. A. (2017). Impact of motivation on job performance of nursing staff in private hospitals in Jordan. International Journal of Academic Research in Accounting, Finance and Management Sciences, 7(2), 54-63.

Al Maqbali, M. R., Al Omari, O., Slimane, S. B. A., \& Balushi, N. A. (2019). The nursing profession in Oman: An overview. Nursing science quarterly, 32(4), 322-325. (Al Maqbali et al., 2019)

AlRaisi, M. Y., AlRawahi, B. S., AlOmrani, N. H., AlHooti, N. K., \& Porkodi, S. (2019). The Effect of Cultural Diversity on Employees' Performance and Productivity in Shell Oman Marketing Company S. A. O. G. International Journal of Multidisciplinary Research and Publications, 1(9), 14-17.

Al Sabei, S. D., AbuAlRub, R., Labrague, L. J., Ali Burney, I., \& AlRawajfah, O. (2021, August). The impact of perceived nurses' work environment, teamness, and staffing levels on nurse-reported adverse patient events in Oman. In Nursing Forum.

Al Salmi, I., \& Hannawi, S. (2018). Health workforce in the Sultanate of Oman: improving performance and the health system. J Int Med Pat Care, 1(1), 6

AlUbaidi, A., AlLawati, J., AlZadjali, S., AlBalushi, M., \& Porkodi, S. (2020). Impact of Emotional Intelligence on Job Performance of Paramedical Employee's in Public Vs Private Hospitals: A Comparison. American Journal of Multidisciplinary Research \& Development (AJMRD), 2(10), 38-45.
Ang S., \& Van Dyne L. (2006) The Impact of Metacognitive, Cognitive and Motivational Cultural Intelligence on Behavioral Cultural Intelligence. International Business \& Economics Research Journal-Third Quarter Volume 16, Number 2.

Australian industry and skills committee (2020). Ambulance and paramedic. Retrieved on February 8, 2020 from: https://nationalindustryinsights.aisc.net.au/industries/health/ambulanc e-and-paramedic.

Barzykowski, K., Majda, A., Szkup, M. and Przyłęcki, P. (2019). The Polish version of the Cultural Intelligence Scale: Assessment of its reliability and validity among healthcare professionals and medical faculty students. PloS one, 14(11), p.e0225240.

Bilal, A \&. Ahmed, W., (2017). The Impact of Emotional Intelligence on Job Satisfaction and Performance in the Healthcare Sector of Pakistan. Retrieved on January 29, 2020 from http://www.qurtuba.edu.pk/jms/default_files/JMS/12_4/09.pdf [7].

Brant, J. M., Al-Zadjali, M., Al-Sinawi, F., Mushani, T., Maloney-Newton, S., Berger, A. M., \& Fink, R. (2021). Palliative Care Nursing Development in the Middle East and Northeast Africa: Lessons from Oman. Journal of Cancer Education, 1-9.

Caputo, A., Ayoko, O. B., Amoo, N., \& Menke, C. (2019). The relationship between cultural values, cultural intelligence and negotiation styles. Journal of Business Research, 99, 23-36.

Charoensukmongkol, P., \& Pandey, A. (2020). The influence of cultural intelligence on sales self-efficacy and cross-cultural sales presentations: does it matter for highly challenge-oriented salespeople? Management Research Review. (Charoensukmongkol et al., 2020)

EMRO, (2010). Health system profile Oman. Retrieved on October $22^{\text {nd }}$, 2021 from: https://apps.who.int/medicinedocs/documents/s17304e/s17304e.pdf

Fata, L., Zabihi Zazoly, A., Gholami, M. and Hazrati, H., 2017. Role of cultural intelligence and job satisfaction in predicting organizational commitment of nurses: A case study. Health_Based Research, 3(1).

Gabel-Shemueli, R., Westman, M., Chen, S. and Bahamonde, D., (2019). Does cultural intelligence increase work engagement? The role of idiocentrism-allocentrism and organizational culture in MNCs. Cross Cultural \& Strategic Management.

Göl, İ., \& Erkin, Ö. (2019). Association between cultural intelligence and cultural sensitivity in nursing students: A cross-sectional descriptive study. Collegian, 26(4), 485-491.

Hughes, M., 2018. Cultural safety requires' cultural intelligence'. Kai Tiaki: Nursing New Zealand, 24(6), pp.24-25.

Jiang, Z., Le, H., \& Gollan, P. J. (2018). Cultural intelligence and voice behavior among migrant workers: the mediating role of leader-member exchange. The International Journal of Human Resource Management, 29(5), 1082-1112.

Maestri, E. Healthcare in Oman Between Past and Present Achievements, Human Security and the COVID-19 Pandemic. Euras Journal of Social Sciences, 77.

Mcombes, S., (2019) Descriptive research. Retrieved on February 19, 2020 from: http://www.scribbr.com/methodology/descriptive-research.

NCSI Monthly Report. (2021 September). Monthly statistical bulletin. Retrieved October 20th, 2021, from: https://www.ncsi.gov.om/Elibrary/LibraryContentDoc/bar_bar_bar_S eptember\%2020203_4599e1fa-d34b-4d63-b42e-47aa18f97476.pdf.

NCSI, (2020). Statistics: Publications of National Center for Statistics Information, Issue.49. Retrieved Oct 25, 2021, from https://www.ncsi.gov.om/Elibrary/

LibraryContentDoc/bar_2021_6e177972-7c32-434d-8258f12c2643961e.pdf.

Porkodi, S., \& Haque, A. (2012). Human Resource Issues: Special Emphasis on Maintenance and Retention of Paramedic Employees In Private Hospitals. Journal of Organisation and Human Behaviour 1 (2), 19-31.

Rahimaghaee, F., \& Mozdbar, R. (2017). Cultural intelligence and its relation with professional competency in nurses. Nursing Practice Today, 4(3), 115-124.

Rahman, M. H., Majumder, S. C., \& Rana, M. (2020). The Reasons Behind the Shift of Patients from Public to Private Hospitals: Evidence from Public Hospitals in Cumilla City Corporation. Int J Pub Policy Admin Res, 7(2), 69-78.

Redha, A., \& Taqi, Z. (2017). An investigation into social media use effect on patient's satisfaction in private hospitals in Oman (Doctoral dissertation, Cardiff Metropolitan University).

Shaibany, S. (2016), Why is Oman a haven of cultural integration? Times of Oman. Available from: https://timesofoman.com/article/84831. [Accessed on:21/10/2021].

Shomoossi, N., Asor, A.A., Kooshan, M. and Rad, M., 2019. Interculturality and cultural intelligence in an academic context: A report from 
European Journal of Business and Management Research www.ejbmr.org

university staff interacting with nursing students. Journal of education and health promotion, 8 .

Sohal, A., de Vass, T., Singh, P., Al Balushi, S., Al Hajri, A. S., Al Farsi, Y., \& Al Arbi, R. (2021). Assessing readiness for lean thinking in healthcare settings: the case for Oman. Industrial Management \& Data Systems.

Steyn, R., \& Solomon, A. (2017). Cultural intelligence: Concepts and definition statements. South African Journal of Business Management, 48(2), 67-74.

Williams, J. (2017). Women vs feminism: Why we all need liberating from the gender wars. Emerald Publishing.

Ziada, K. E., van der Linden, D., Dutton, E., Almalki, N. S., Bakhiet, S. F. A., Ihsan, Z., Furnham, A., Essa, Y. A. S., Alqafari, S. M., Alsahli, D. S., \& Aljbr, A. S. R. (2021). Sex and Culture Differences in Cultural Intelligence: A Study Comparing Saudi Arabians and Egyptians. SAGE Open, 11(3).

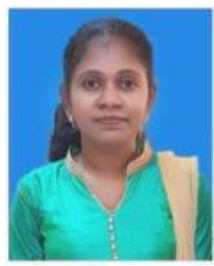

Dr. S. Porkodi is currently employed as faculty in the University of Technology and Applied Sciences(HCT), Muscat, Sultanate of Oman. She holds academic degrees in M.B.A., M.Phil(Ent). M.Phil(Mgt)., PG.D.PM\&IR., PG.D.HM., PG.D.EM., Ph.D. She has authored 11 books in the fields of Hospital administration and Business studies. She has contributed to prestigious periodicals and published numerous papers in reputable international and national journals. She served as an Editor of a referred Journal-Managemen Stream, Editor-in-Chief of International Journal of Management Rivulet, and Editor of International Journal of Management, Entrepreneurship and Technology, New York.

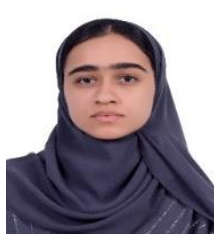

Amna Sbail Abdulrahim Al Zadjali, 24 years old she's currently a Bachelor degree student in Human Resources Management at University of Technology and Applied Science (HCT), Muscat, Sultanate of Oman. She interested in reading books about selfdevelopment to be a good manager in the future as well as she has the ability to work in teams.

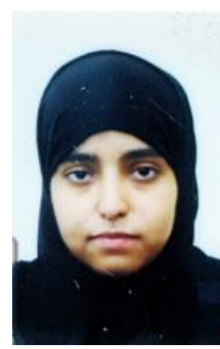

Yasemain Mohammed Khalfan Ali AL Nabhani is currently a last year student in Human Resource Management at university of Technology, Muscat Sultanate of Oman. Since childhood she was always interested in reading books and novels with various titles about life and development. Her future plan is to find job to accomplish the desire needs of skills and development as she will graduated soon from the university.

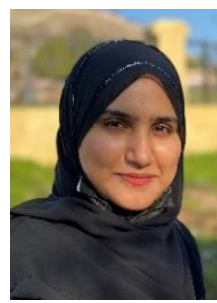

Fatma Salim Abdullah Alrahbi, 26 years old. She is currently a bachelor's degree student in Human Recourses Management at University of Technology and Applied Science, Muscat, Saltant of Oman. She is interested in art, research, and exploration in detail. She also can manage business, work under pressure and working in a team. 